\title{
OBESITY IS INCREASING FAST AMONG VARNA SCHOOL CHILDREN IN THE LAST 5 YEARS (2002-2007)
}

\author{
Iotova V., S. Galcheva, K. Petrova ${ }^{1}$ \\ Dept. of Pediatrics and Medical Genetics, ${ }^{1}$ Dept. of Hygiene and Ecology \\ Medical University - Varna
}

Reviewed by: Assoc. Prof. V. Madjova

\begin{abstract}
Childhood obesity persists and increases with age, thus leading to early morbidity and mortality. Countries on the Balkans report extremely high rates of growing childhood obesity with time, especially in pre-pubertal children. The present study aims to assess trends of obesity increase among pre-pubertal children during the last 5 years (2002-2007) in the city of Varna. Two representative cross-sectional student's populations aged 7-9 years were compared - one measured in 2001/2002 (Gr. I, $n=1004$ ) and Gr. II, $n=1043$, studied in 2006-2007. Both groups were measured using standard procedures. The prevalence of obesity is most markedly expressed, especially right before puberty among the 9 year old children. It has greatly increased in 5 -years time under surveillance, significantly both among boys $(p<0.001)$ and among girls $(p=0.0027)$. There is no significant difference in obesity prevalence between girls and boys $-10.4 \%$ vs. $10.6 \%(p>0.05)$. Both mean BMI and the level of the BMI $95^{\text {th }}$ percentile are steeply increasing. The mean BMI of the mothers is lower in $2007\left(22.0 \pm 2.6 \mathrm{~kg} / \mathrm{m}^{2}\right)$ than it was in $2002\left(22.8 \pm 2.5 \mathrm{~kg} / \mathrm{m}^{2}\right), \mathbf{p}<0.01$. The mean BMI of the boys' fathers doesn't change while the girls' fathers show significant BMI increase $-25.00 \pm 3.7 \mathrm{vs} .26 .9 \pm 2.9 \mathrm{~kg} / \mathrm{m}^{2}$ $(p<0.001)$. In a linear regression analysis the most significant factors for obesity for Gr. I are BMI of the mother $(p<0.0001)$, father $(p<0.0001)$ and number of family members $(p=0.001)$ and for Gr. II - birth weight $(p<0.0001)$, family history $(p<0.0001)$, decreased frequency $(p=0.001)$ and duration $(p=0.01)$ of physical activity, and increased sodas consumption $(\mathrm{p}=\mathbf{0 . 0 3 5})$. The present study provides evidence of increasing obesity among pre-pubertal children in the city of Varna. More regulations should be introduced in order to prevent/reverse the trend towards increase of childhood obesity.
\end{abstract}

Key words: obesity, childhood, trend of increase, BMI, risk factors

Childhood obesity tends to persist and increase with age, thus leading to early morbidity and mortality among different world populations. In the last decades obesity among children and adolescents is showing sustained trend towards increase in most European countries posing considerable health risks and creating the notion of an obesity epidemics needing special measures to prevent world health crisis (18). Countries on the Balkans surrounding Bulgaria report extremely high rates of growing childhood obesity with time, especially among young prepubertal children $(16,23)$. Previous studies conducted in the city of Varna show relatively low prevalence of obesity (2), though overweight was even then high compared to international BMI reference data $(7,13)$. Changing life-style and increasing sedentary behaviours mandate the need of constant monitoring of the obesity trends, especially among children. The aim of the present study is to assess trends of obesity increase among pre-pubertal children during the last 5 years (2002-2007) in the city of Varna.

\section{STUDY POPULATIONS AND METHODS}

For the purposes of the current study 2 representative cross-sectional student's populations were compared. The inclusion and exclusion criteria were the same for both study populations. Inclusion criteria were permanent residence in Varna, presence at school on the day of the measurement and assent to participate. Only children with severe debilitating diseases like bone dysplasias, genetic syndromes, etc., as well as obvious mental retardation were excluded. Both studies were approved by the local office of the Ministry of Education.

The first study evaluated children aged 7-9 years (before their $10^{\text {th }}$ birthday) from unselected Varna schools who were included in a project to compare childhood obesity on the Balkans (unpublished data). They were born in 1992-93, measured in 2001/2002 and here we would refer to them as group I (Gr. I). After applying inclusion/exclusion criteria a total of 1004 children took part in the study. 
The second group (Gr. II) was studied in 2006-2007 as a part of a population-based project to create waist circumference reference for Bulgarian children. Again, all the children included in the present comparative study $(n=1043)$ were prepubertal aged 7 to 9 years (before their $10^{\text {th }}$ birthday) and strictly complying with the inclusion/exclusion criteria.

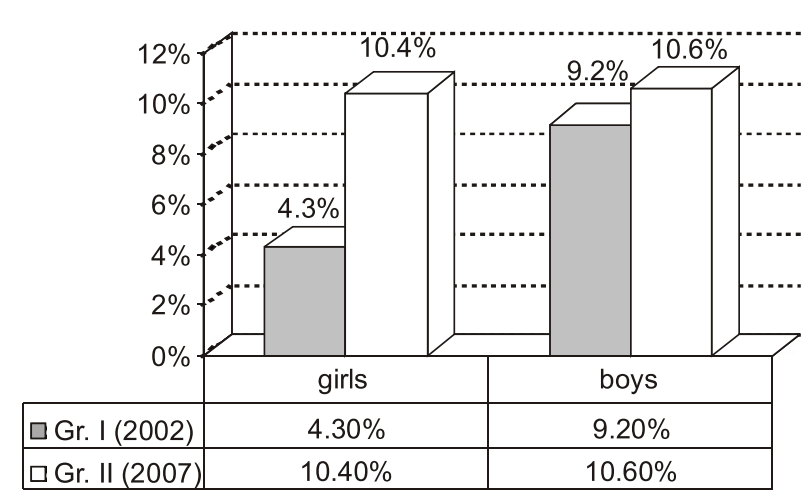

Fig. 1. Increasing obesity prevalence among 9 years old prepubertal children (2002-2007)

Both groups were measured from investigators authoring this paper and using standard procedures. The children were barefooted or in socks only, and the head was put in the so called "Frankfurt plane" position. A portable stadiometer (Tanita 2000) was used for the measurements of height, while weight was assessed using the school meters for the first group and a single portable one (Seca) for the second group. The height $(\mathrm{m})$ and weight $(\mathrm{kg})$ data were used to calculate BMI $\left(\mathrm{kg} / \mathrm{m}^{2}\right)$ and the figures were compared to International Obesity Task Force BMI reference available for international comparisons (6).

Both datasets contained data gathered through questionnaire about the current height/weight (resp. BMI) of both parents (self-reported), their level of education, the number of family members, family history of obesity, daily hours in front of the television set, and computer time only for Gr. II. The latter also provided data about the frequency and duration of daily/weekly physical activity, birth weight, and fizzy drinks consumption.

All the data comparisons and analyses are done using the statistical package SPSS 11.0 for Windows.

\section{RESULTS}

The gender distribution in both datasets is equal, Gr. I consisting of 490 boys (51.2\%) and 514 girls (48.8\%), $\mathrm{p}>0.05$, and Gr. II - 544 boys (47.8\%) and 499 girls (52.2\%), $\mathrm{p}>0.05$.

The prevalence of obesity is most markedly expressed, especially right before puberty among the 9 year old children (Fig. 1). It has greatly increased in 5-years time under surveillance, significantly both among boys $(\mathrm{p}<0.001)$ and among girls $(\mathrm{p}=0.0027)$. At present there is no significant difference in obesity prevalence between girls and boys $10.4 \%$ vs. $10.6 \%$, resp. ( $\mathrm{p}>0.05)$.

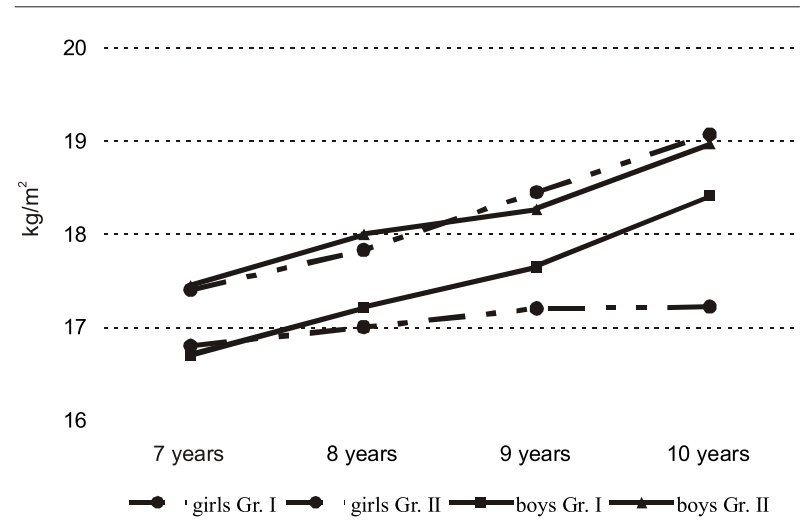

Fig. 2. BMI dynamics with age by group (Gr I vs. Gr. II)

The students from both sexes showed increasing mean BMI with age (Fig. 2). This phenomenon is characteristic for both studied groups, but at a higher BMI level in 2007. The most strongly expressed increase is found among girls from the Gr. II.

It is obvious that not only the prevalence of obese children has increased but also the extent of their obesity has quickly increased in the 5-year period under study. It is reflected by the augmentation of the mean BMI in the boys $(\mathrm{p}=0.001)$, as well as in the girls ( $p=0.001)$, Fig. 3. The same evidence in a more convincing manner is found when comparing the $95^{\text {th }}$ BMI percentiles by age (Fig. 4). Except for the youngest students (7 years old), the $95^{\text {th }}$ BMI percentile is significantly higher in both sexes $(p<0.01)$.

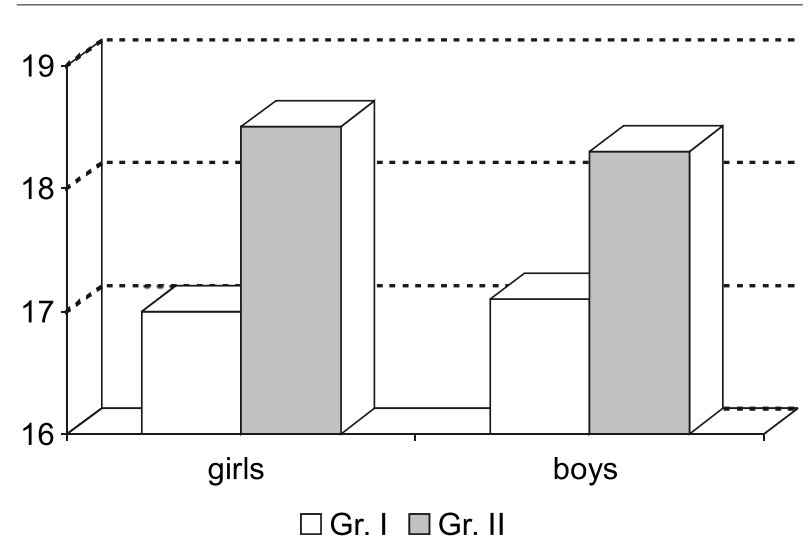

Fig. 3. Trend towards BMI increase with time (2002-2007).

Comparing BMIs of the parents, we found that the mean BMI of both girls' and boys' mothers is lower in 2007 (22.0 $\left.\pm 2.6 \mathrm{~kg} / \mathrm{m}^{2}\right)$ than it was in $2002\left(22.8 \pm 2.5 \mathrm{~kg} / \mathrm{m}^{2}\right), \mathrm{p}<0.01$. The mean BMI of the boys' fathers doesn't change while the girls' fathers show significant BMI increase - 25.00 \pm 3.7 vs. $26.9 \pm 2.9 \mathrm{~kg} / \mathrm{m}^{2}(\mathrm{p}<0.001)$.

In a linear regression analysis the most significant factors for the presence of obesity for Gr. I are BMI of the mother ( $\beta=0.229, p<0.0001)$, father $(\beta=0.18, p<0.0001)$ and number 
Obesity is increasing fast among Varna school children in the last 5 years ...

of family members $(\beta=-0.076, p=0.001)$. The education of the parents doesn't seem to play a role $(\mathrm{p}>0.05)$.
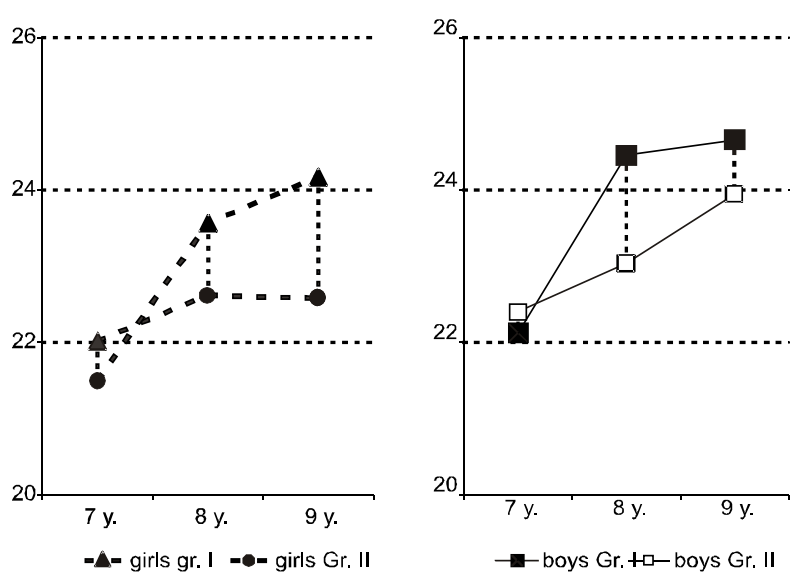

Fig. 4. Comparison between $95^{\text {th }}$ BMI percentiles with age and time interval (2002-2007).

For Gr. II the most important variables turn out to be birth weight ( $\mathrm{p}<0.0001$ ), family history (first degree relatives) of obesity $(p<0.0001)$, decreased frequency $(p=0.001)$ and duration $(\mathrm{p}=0.01)$ of physical activity, and increased fizzy drinks consumption $(\mathrm{p}=0.035)$.

\section{DISCUSSION}

The present study gives solid evidence about the increasing childhood obesity prevalence among pre-pubertal children living in an urbanized city area in a relatively short period of time - 5 years. Nowadays every $10^{\text {th }}$ child 9 years old is obese. Most of the published studies are cross-sectional like ours, but present the prevalence at a certain point of time $(7,10)$. One of the strong sides of the current study is the possibility to compare children's cohorts born and looked after in one and the same area at one and the same age points. This strengthens the conclusions about increasing obesity. Other workers from different countries have unequivocally found the same trend in the past decades though most of them at a much higher level $(15,19,20,23)$.

The lack of difference between the genders is a somewhat new finding. In adults male prevalence is reported from the Balkans (4), and among adolescents some authors find also male preponderance $(15,16)$. Furthermore, most of the research in pre-pubertal children finds more expressed increase in boys (20). Our previous study (13) also found difference with the male sex much more affected than females $-9.2 \%$ vs. $4.3 \%$ at 9 years of age $(p<0.05)$. The present data mean much more rapid trend of increase among girls that could be to some extent related to earlier onset of puberty like the reported by Gelbrich et al. (10). However, we have previously published data about stable and even slightly increasing age at menarche among girls compared to previous Bulgarian studies (12). The significance of this increase definitely deserves further exploration and applying longitudinal study design.
Not only the relative share of obese children has increased but also the cumulative fat mass as reflected by children's BMIs has increased significantly in the 5 years time. Since there are a lot of data and publications supporting the usefulness of BMI as the main parameter to evaluate obesity, also in childhood (14), we regard these results as very alarming. The relatively bigger increase among girls is even more bothering. In a recent paper Sewell at al. provide evidence about "imprinting" of obesity in the offspring of obese women (21) - the children of obese women have less lean and more fat mass already at birth. There are also data about obstetric complications and remote health consequences such as breast cancer specific for obese women. Another alarming trend is the pronounced increase in the $95^{\text {th }}$ BMI centile, especially among 8 and 9 years old students. This means that the relative grade of the obesity of obese children increases, hence more and earlier co-morbidities could be expected. This is found also in other populations (11), and in fact the frequency of metabolic syndrome, one of the major identifiable risk factor clusters in childhood, is increasing in parallel thus posing major and undisputable health threats for the future (22). This very fast increase really puts forward the question how often the anthropometric references should be renewed.

One of the unexpected findings was the BMI decrease in the mothers of all students. In other studies from different parts of the world this is related to socioeconomic status, more educated and wealthy parents having less obese children while obesity is much more prevalent among lower socioeconomic groups $(5,24)$.

Similar patterns are also found about smoking and physical inactivity as well as more time for TV viewing (10). If education is still a good correlate of social status in our society, obviously this is not true for a recently developed country like ours and deserves further exploration. The significant increase of girls' fathers BMI with time is in concert to faster increasing female obesity, thus implying more to a relationship between increasing societal wealth and childhood obesity. The same was reported by do BlouzaChabchoub et al. from Tunesia (8) and maybe more typical for developing economics, or may alternatively reflect more aggressive marketing of unhealthy foods and life-styles in societies with less strict regulations (9).

Looking towards the possible contributors for the fast obesity increase the strongest underlining factor is parental obesity/family history. Of course, this is telling us about possible genetic determinants but also about the influence of the home/built environment (17) upon the accumulation of fat mass in the children. As recently published by Christakis\&Fowler, the neibourhood/non-genetic close environment has great impact on the obesity development "network phenomenon" in such strictly defined and followed cohort as the Framingham Heart study cohort is (6). One of the most intriguing although not unexpected findings from the current study is the direct correlation between less frequent and shortened physical activity and obesity, even in these relatively young children. Ball et al. (3) report the same correlation only in boys in whom physical inactiv- 
ity is a major contributor for obesity. Since their study group is the same age as ours, we also assume that physical inactivity together with TV viewing and computer time could have greater influence upon male obesity. This fact has great prevention implications.

The present study provides sound evidence of greatly increasing obesity among pre-pubertal children in the city of Varna. Since the general practioners (1) and the society as a whole are not yet ready to recognize this threat to the public and individual health, we believe more timely and strict regulations, both societal and political, should be introduced in order to prevent and try to reverse the trend towards increase of childhood obesity.

\section{REFERENCES}

1. Галчева С., Йотова В., Маджова В., Цанева В. Подход към детско-юношеското затлъстяване в общомедицинската практика. Социална медицина 2006, кн. 4: 7-11

2. Йотова В., К. Петрова, В. Цанева. Честота и риск от затлъстяване сред зрелостници от гр. Варна. Педиатрия 2005, 1: 31-34

3. Ball EJ, O'Connor J, Abbott R et al. Total energy expenditure, fatness and physical activity in children aged 6-9 years. Am J Clin Nutr 2003, 74(4): 524-28

4. Bertsias G., Mammas I., Linardakis M, Kafatos A. Overweight and obesity in relation to cardiovascular risk factors among medical students in crete, Greece. BMC Public Health 2003, 3: 3

5. Blouza-Chabchoub S, Rached-Amrouche C, Jamoussi-Kammoun H, Bouchaa N. Frequency and risk factors of obesity in Tunisian adolescent. $T u$ nis Med. 2006, 84(11): 714-6

6. Christakis N, Fowler J. The spread of obesity in a large social network over 32 years. $N$ Engl J Med 2007, 357(4): 370-79

7. Cole T, Bellizi M, Flegal K, Dietz W. Establishing a standard definition for child overweight and obesity worldwide: international survey. BMJ 2000, 320: $1240-43$

8. Do Carmo I, Dos Santos O, Camolas J et al. Overweight and obesity in Portugal: national prevalence in 2003-2005. Obes Rev 2008, 9(1): 11-9

9. Galcheva SV, Iotova VM, Stratev VK. Television food advertising directed towards Bulgarian children. Arch Dis Child. 2008, 93(10): 857-61

10. Gelbrich G., Bluher S., Reich A., et al. Prevalence of obesity and elevated blood pressure as well as onset of puberty in German School Children Attending different educational tracks. Horm Res 2008, 70: $340-48$
11. Huerta M, Gdalevich M, Haviv J et al. Ten-year trends in obesity among Israeli schoolchildren: 1990-2000. Acta Paediatr 2006, 95(4): 444-9

12. Iotova V, K Petrova, V Tzaneva. Secular Trends in Growth of the Contemporary Adolescents. Acta Morphol Anthropol 2001, 6: 172-76

13. Iotova V., V. Tzaneva, K. Petrova, Y. Yotov. Ten-year trend of obesity among primary-school children in Bulgaria. Horm Research 2003; 60 (suppl 2): 128

14. Korner A., Gelbrich G, Miller G. et al. Critical evaluation of methods for determination of body fat content in children: back to basic parameters?

Horm Metab Res 2007, 39: 31-40

15. Krassas G., Tzozas T., Tsamatis C., Konstantinidis T. Prevalence and trends in overweight and obesity among children and adolescents in Thessaloniki, Greece. J Pediatr Endocrinolo Metab 2001, 14(5):1319-26

16. Krassas GE, Tsametis C, Baleki V et al. Prevalence of overweight and obesity among children and adolescents in Thessaloniki-Greece and Kayseri-Turkey. Pediatr Endocrinol Rev 2004 Aug; 1 Suppl 3: 460-4

17. Lobstein T. Child obesity: what can be done and who will do it? Proc nutr Soc 2008, 67(3): 301-6

18. Lobstein $\mathrm{T}$. The prevention of obesity in children. Pediatr Endocrinol Rev 2004 Aug; 1 Suppl 3: 471-75

19. Martinez-Vizcaino V, Sanchez Lypez M, Moya Martinez $\mathrm{P}$ et al. Trends in excess weight and thinness among Spanish schoolchildren in the period 1992-2004: the Cuenca study. Public Health Nutr. 2008 Aug 27:1-4

20. Meigen C, Keller A, Gausche R et al. Secular trends in body mass index in German children and adolescents: a cross-sectional data analysis via CrescNet between 1999 and 2006. Metabolism. 2008, 57(7): 934-9

21. Sewell M., Nuston-Presley L., Super D., Catalano P. Increased neonatal fat mass, not lean body mass, is associated with maternal obesity. $\mathrm{Am} \mathrm{J}$ Obstet Gynecol 2006, 195(4): 1100-13

22. Sun S, Liang R, Huang T et al. Childhood obesity predicts adult metabolic syndrome: the Fels Longitudinal Study. J Pediatr 2008, 152(2): 191-200

23. Turkkaraman D, Bircan I, Tosun O, Saka O. Prevalence and risk factors of obesity in school children in Antalya, Turkey. Saudi Med J 2006, 27(7): 1028-33

24. Wang Y, Beydoun M. The obesity epidemic in the United States-gender, age, socioeconomic, racial/ethnic, and geographic characteristics: a systematic review and meta-regression analysis. Epidem Rev 2007, 9: $6-28$ 